\title{
Electrical stimulation of human hair follicles via microelectrodes*
}

\author{
BERTRAM SCHARF, JUHANI HYVÄRINEN, ANTTI PORANEN \\ Institute of Physiology, University of Helsinki, Helsinki 17, Finland \\ and \\ MICHAEL M. MERZENICH \\ School of Medicine, University of California, San Francisco, California 94122
}

\begin{abstract}
Trains of electrical pulses were applied to hair follicles on the forearm by microelectrodes with tip diameters less than $5 \mu$. Clear, painless, vibratory sensations could be evoked by stimulating the middle of a follicle. Exponents of the individual power functions relating vibratory magnitude and electric current ranged from 3.1 to 7.4 . Absolute thresholds varied little with pulse frequency but did vary from $S$ to $S$ and from one electrode placement to another. Pitch discrimination was very poor; Ss could not distinguish 40 from $80 \mathrm{pps}$. Pain was of ten present, but the manner of its appearance suggested an anatomical segregation between vibratory and pain receptors.
\end{abstract}

Since early in the 20th century, investigators have attempted to bypass sensory transducers and to directly excite discharges in nerve fibers and endings by stimulating the skin electrically (e.g., Adrian, 1915; Beck \& Rosner, 1968; Bishop, 1943; von Frey, 1915; Piéron \& Segal, 1938; Stevens, Carton, \& Shickman, 1958). The primary goal has been to distinguish neural events from transducer events in sensory coding and adaptation. Our goal is the same, but we have simplified the experimental parameters. Instead of gross electrodes that cover at least several square millimeters of skin and stimulate large numbers of receptors and neural elements, we have used microelectrodes in an attempt to limit stimulation to a single neural unit. It was our hope that the coding of vibratory magnitude and pitch could thus be studied on the level of single peripheral fibers in conscious human Os. This report describes techniques for the stimulation of hair follicles via microelectrodes, and our early results concerning sensitivity, subjective magnitude, pitch, and adaptation.

\section{PROCEDURE}

\section{Electrodes and Insertion}

Because of their toughness, we used tungsten microelectrodes (Hubel, 1957) covered with lacquer (Araldite 985-F, Ciba). Tungsten wire, $100 \mu$ in diam, was etched electrolytically for a distance of $5 \mathrm{~mm}$ to a fine, gradual taper so that $100 \mu$ from the tip the diameter was reduced to about $30 \mu$. Coating was done with tip upward under microscopic observation in order to regulate the bare area. Bare tip lengths ranged from 20 to $200 \mu$. The ac impedances were measured with a $1,000-\mathrm{Hz}$ sine wave and ranged from 50 to $500 \mathrm{k}$ ohm.

The base of the electrode was inserted in 28-ga ( $350 \mu$ outside diam) hypodermic tubing. The bare tip of an isolated, thin,

* Research conducted while the senior author was on leave from Northeastern University, Boston, Massachusetts 02115. Part of this work was supported by a grant from the Foundations' Fund for Research in Psychiatry to J. Hyvärinen, who is a research fellow of the National Research Council for Medical Sciences, Finland. Requests for reprints should be sent to either B. Scharf in Boston or J. Hyvärinen in Helsinki. flexible wire was introduced into the opposite end of the tubing and clamped in place. The other end of the wire was attached to the lead from the negative output of a constant-current stimulator.

The $\mathrm{S}$ seated himself comfortably and laid his left forearm in a box of sand. In our first experiments, the electrode was mounted in a micromanipulator and inserted under a forearm hair along the follicle path. Eventually, we found that the insertion proceeded much faster when the $S$ held the electrode with a tweezer and inserted it manually. Either he or the $E$ observed the electrode under a binocular microscope at $16 \mathrm{X}$ or $25 \mathrm{X}$ magnification. During insertion, electric pulses were applied intermittently at 40 pps. When the $S$ felt a vibratory sensation, he began to manipulate the electrode until the sensation was clearest and painless. The $\mathrm{E}$ then dropped melted bone wax around the electrode to hold it in place. Once fixated, the electrode could be maintained apparently indefinitely, although most Ss could make psychophysical judgments for no more than 1 or $2 \mathrm{~h}$. Because the skin could not be totally immobilized, it tended to follow the movement of the electrode into the skin. Therefore, depth measurements with a microdrive scale were inaccurate. Somewhat more accurate measurements, approximately $\pm 100 \mu$, could be made by microscopic observation of insulation drops located on the electrode shaft at known distances.

\section{Stimuli}

Stimuli were $0.5-\mathrm{msec}$, square-wave pulses from a Kistner pulse generator (Types 421 and 422) sent through a decade attenuator to a constant-current generator whose maximum output was $400 \mu \mathrm{A}$. The current was monitored across a $1,000-\mathrm{ohm}$ resistor placed in series with the microelectrode.

\section{Psychophysical Methods}

(l) Thresholds were measured by the method of limits as a function of the pulse frequency of trains of single pulses and also of the time separation, $\Delta T$, between double pulses repeated every $25 \mathrm{msec}$ ( 40 double pps). See Fig. 1.

(2) Subjective magnitude was measured by the method of magnitude estimation without a designated standard. Ss assigned numbers to the strength of 1 -sec trains of single pulses presented at 5 to 10 current levels above threshold. In a separate series. Ss judged double pulses.

(3) Adaptation was also measured by magnitude estimation. As soon as the stimulus came on, the $S$ assigned a number to its subjective strength and continued to do so every few seconds until he no longer felt the stimulus or until $3 \mathrm{~min}$ had gone by. 


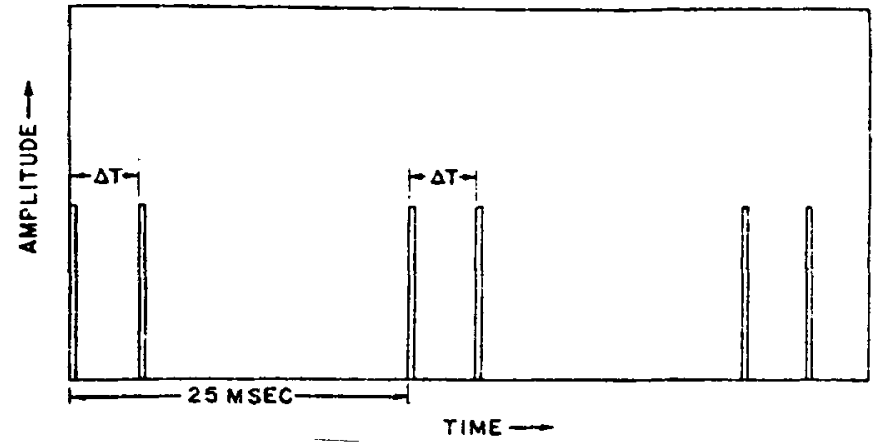

Fig. 1. Example of sequence of double pulses presented at a rate of $40 \mathrm{pps}$. The time interval, $\Delta T$, was varied.

(4) Differences in pitch were measured by a ratio method. Two 1-sec pulse trains were presented successively at different frequencies or with different $\Delta T$ s. The $S$ estimated the pitch ratio between the two trains.

\section{Subjects}

Seven men served as Ss, including three of the authors, but not every $\mathrm{S}$ was tested with all four psychophysical methods.

\section{RESULTS}

\section{Quantitative Results}

For a given electrode placement and $S$, the detection threshold could be precisely measured in steps of about $5 \mu \mathrm{A}$. The lowest threshold was $6 \mu \mathrm{A}$, but most were between 100 and $200 \mu \mathrm{A}$. Threshold varied little between frequencies of 10 and 1,100 pps and for $\Delta \mathrm{Ts}$ between 2 and $12.5 \mathrm{msec}$.

Estimations of pure vibratory magnitude were restricted to an intensity range equal to about two to three times the threshold value. Further increasing the current produced a pricking sensation and then sharp pain. The measurable range was even smaller when threshold was greater than $150 \mu \mathrm{A}$, because the constantcurrent generator cut off at $400 \mu \mathrm{A}$, before pricking usually began.

The estimations in Fig. 2 are for 40-pps stimuli that produced a vibratory sensation with neither pricking nor pain. Each point is the mean of two judgments by a given S. Except for averaging, the numbers given by the $S$ are shown unaltered on the ordinate. Current at the electrode is indicated on the abscissa. Straight lines were drawn through the data by visual inspection. Exponents for these power functions vary from 3.1 to 7.4. Three Ss show a distinct flattening of the function above $200 \mu \mathrm{A}$. Similar functions were generated by double pulses at a rate of 40 double pps with a $\Delta \mathrm{T}$ of $5 \mathrm{msec}$.

The course of adaptation is clearly shown by the independent set of magnitude estimations obtained under continuous stimulation. During the first $10 \mathrm{sec}$ of stimulation, magnitude declined slowly if at all; then the magnitude declined in approximately direct proportion to elapsed time. Threshold was reached for two Ss after 20 to $60 \mathrm{sec}$, but the third $S$ reported a weak sensation after $3 \mathrm{~min}$. However, these rates and times must also depend on stimulus level, which was not varied.

The pitch judgments, although limited in scope, clearly indicated poor pitch discrimination. Of five Ss, only two could reliably distinguish 80 from 40 pps. Only one $S$ reported a consistent pitch difference between 40 single pps and 40 double pps when $\Delta T$ was varied from 2 to $10 \mathrm{msec}$. (Informal measurements do suggest that discrimination improves at low frequencies.)

\section{Qualitative Results}

Electrical stimulation of hair follicles often did not elicit a clear vibratory sensation; in some follicles only pain was aroused. Usually, moreover, the stimulation of

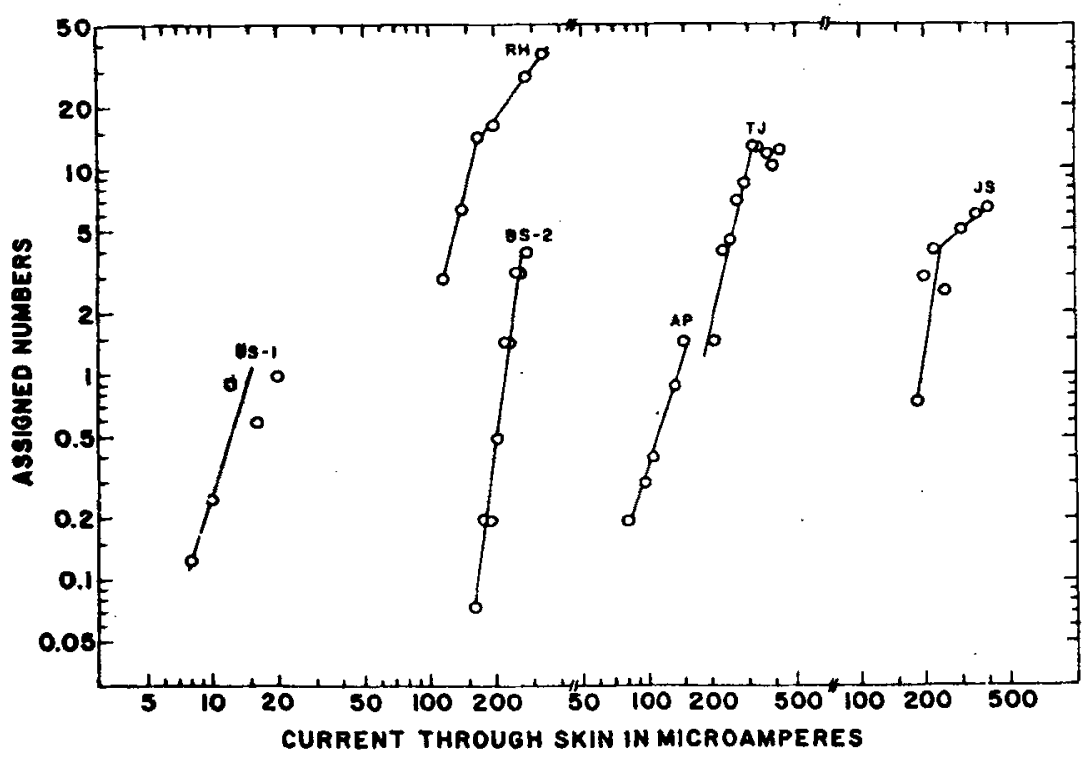

Fig. 2. Magnitude estimations of electrical pulses applied at a rate of $\mathbf{4 0}$ pps to the hair follicles. Functions are for individual Ss. Each point is the mean of two judgments. 
the superficial part of the follicle, at depths of 100 to $500 \mu$, and of the deepest parts, at depths of 1,500 to $2,000 \mu$, produced intense pain. Even this intense pain left no aftersensation. The best mechanical sensations were elicited at a depth of about 500 to $1,500 \mu$ in most follicles of the big guard hairs. The smaller down-hair follicles, which we occasionally tried, produced pain sensations. Often a local reddening and sweating response could be observed under the microscope when the stimulus became painful. Such autonomic reactions were particularly prominent in some Ss.

Electrical stimulation was also applied superficially with needle electrodes on the forearms of three Ss. Only pure pain or a painful vibratory sensation could be elicited. On none of many stimulated spots did electrical stimulation give rise to the painless vibratory sensation so common within a hair follicle.

\section{DISCUSSION}

Despite the use of electrodes with a tip diameter less than $5 \mu$, we apparently excited more than a single receptor or neural unit. This inference follows from the following considerations. The all-or-none law of nerve action tells us that a single neural unit can signal an increase in stimulus magnitude only by faster firing. However, this code is not available in discrete electrical stimulation (except, perhaps, close to threshold), since, regardless of its level above threshold, each electrical pulse would excite one and only one neural discharge in a given unit. Hence, once the stimulus current is high enough to stimulate a neural discharge to every 0.5 - msec pulse, further increasing the current cannot affect the discharge rate; the nervous system would then have no way of signaling the increase in current, and subjective magnitude could not change. Since, in fact, subjective magnitude did increase as current rose to levels three to four times above threshold, we are forced to conclude that increasing the current recruited additional units. The firing of these units signaled increased stimulus magnitude. (These additional units may require higher currents before firing because they have higher inherent thresholds or, more likely, because they are located farther from the electrode than are those units which respond to weaker stimulation.)

Even at threshold, more than one unit may have fired, since the currents were usually more than needed to stimulate a single nerve fiber. According to calculations by Zotterman (cited by Piéron, 1967), $5 \mu \mathrm{A}$ is needed to excite a neuron. This value is similar to the threshold for the electrical excitation of a single intracortical neuron whose membrane is touched by a microstimulator (Stoney, Thompson, \& Asanuma, 1968). In our study, only one electrode placement yielded a threshold near $5 \mu \mathrm{A}$. The rest of the time, thresholds were above $50 \mu \mathrm{A}$ and usually above $100 \mu \mathrm{A}$. These high values suggest that the microelectrode normally did not contact a single neural unit, but that the stimulus current spread in the tissues, simultaneously exciting each of a number of units with a fraction of the total current applied.

Whatever the physiological basis for these results, there is no doubt that once threshold is exceeded vibratory magnitude grows very rapidly with electric current. The exponents of the lower limbs of the individual power functions are larger than the average exponent of 3.5 measured with large surface electrodes by Stevens, Carton, and Shickman (1958), and are much larger than the 1.8 measured by Ekman et al (1964). Ekman et al covered a relative stimulus range nearly double that used in either the Stevens or in the present study, and they included quite painful stimuli. Rosner and Goff (1967), also using macroelectrodes, obtained magnitude estimations that yielded double-limbed power functions like those of Ss R.H. and J.S., but not as steep. They also measured, in the median nerve, evoked potentials and neural electrical responses that had flat upper limbs very much like T.J.'s function. Apparently, our microelectrode stimuli tapped mainly the lower limb of the double-limbed electrocutaneous power function. Beck and Rosner (1968) and Ekman et al (1966) have treated their macroelectrode data as single power functions whose steep lower portions can be eliminated by introducing a "threshold correction" (Scharf \& Stevens, 1961); our data are too limited to permit a choice between single- and double-limbed functions.

The power functions were obtained with $1-\mathrm{sec}$ pulse trains. Longer lasting stimuli resulted in a decline in the vibratory magnitude. This decline suggests that adaptation occurs beyond the peripheral fibers, since the response of an intact fiber to direct electrical stimulation remains invariant (cf. Hodgkin, 1964).

Although our stimulus range was limited by the constant-current generator at our disposal, usually we could not have raised the current more than another $50 \%$ to $100 \%$ without encountering pain. When threshold was low, pain appeared at a level about three times above threshold, the same relative level reported by Piéron and Segal (1938) for a macroelectrode on the middle finger. This agreement plus the gross similarity of our exponents with some of those in the literature suggest that electrical stimulation by micro- and macroelectrodes has very similar effects.

In general, with both kinds of electrode, a preponderant response from the skin seems to be "fast" or "pricking" pain. With microelectrodes, pain could be avoided and a pure mechanical sensation evoked only by stimulating in the middle part of a hair follicle, where the palisade and circumferential fiber endings are located. Even then, not every follicle yielded a painless sensation. These findings not only stress the importance of pain in the skin as compared to mechanoreception, but also suggest anatomical segregation of these two modalities. Although such a segregation is not obvious in the hair follicle's dense network of fiber terminals seen with silver impregnation (Winkelmann, 1960) or a stain for cholinesterase (Horn. 1970), it is known that delta 
afferents, which mediate "fast" pain, distribute to the skin about the tops of hair follicles and between hairs (Merzenich \& Harrington, 1969). Moreover, we did observe physiological responses that support the distinction between vibration and pain. In many of our Ss, painful stimuli caused a sudden reddening (vasodilation) around the electrode together with the secretion of droplets from openings of the sweat glands. Since only very painful stimuli evoked such reactions, their physiological basis could be activation of $\mathrm{C}$ fibers with antidromical conduction, known as the axon reflex, to cutaneous blood vessels (cf. Bard, 1968, pp. 169-171).

When pain was absent, the vibratory sensation from a good electrode locus within a follicle was distinct and crisp. We were, therefore, surprised to find that pitch discrimination of electrical vibration was much poorer than discrimination of mechanical vibration, as measured by Goff (1967) and Mountcastle et al (1969). Of five Ss who made pitch judgments, only two reliably distinguished 80 pps from 40 pps. Using a gross surface electrode, Piéron and Segal (1938) also found poor frequency discrimination for electrical pulses on the finger, although the discrimination of electrical sine waves (ac) is good (Monjé, 1938). What could be the physiological basis for the weakness of the discrimination of electrical square-wave pulse trains as compared with electrical or mechanical sine-wave trains? (No one seems to have measured the discrimination of mechanical square waves.) Perhaps the difference lies in the form of the peripheral nerve activity. Sine waves evoke smooth, continuously varying neural responses. Square waves evoke steeply pulsed nerve volleys that alternate with periods of no activity in the participating afferent fibers. It is just possible that this discontinuous (and unnatural) activity is more difficult for a central synaptic mechanism to handle than is smooth continuous activity. In the auditory system, discrimination between low frequencies is good even for pulsed sounds, but such square waves are smoothed, without loss of timing information, in the graduated response along the basilar membrane. Since the skin also smooths mechanical square-wave stimuli, frequency discrimination ought to be good for such low-frequency inputs, leaving only electrical square-wave stimuli as difficult to discriminate.

\section{REFERENCES}

Adrian, E. D. The response of human sensory nerves to currents of short duration. Journal of Physiology (London), 1919, 53, 70-85.
Bard, P. Control of systemic blood vessels. In V. B. Mountcastle (Ed.), Medical physiology. Vol. I. (12th ed.) St. Louis: Mosby, 1968.

Beck, L., \& Rosner, B. S. Magnitude scales and somatic evoked potentials to percutaneous electrical stimulation. Physiology \& Behavior, 1968, 3, 947-953.

Bishop, G. H. Responses to electrical stimulation of single sensory units of skin. Journal of Neurophysiology, 1943, 6, 361-382.

Ekman, G., Frankenhauser, M., Levander, S., \& Mellis, I. Scales of unpleasantness of electrical stimulation. Scandinavian Journal of Psychology, 1964, 5, 257-261.

Frey, M. von Physiologische Versuche über das Vibrationsgefüh1. Zeitschrift für Biologie, 1915, 65, 417-427.

Goff, G. D. Differential discrimination of frequency of cutaneous mechanical vibration. Journal of Experimental Psychology, 1967, 74, 294-299.

Hodgkin, A. L. The conduction of the nervous impulse. Liverpool: Liverpool University Press, 1964.

Horn, R. N. VAN Vibrissae structure in the rhesus monkey. Folia Primatologica, 1970, 13, 241-285.

Hubel, D. H. Tungsten microelectrode for recording from single units. Science, $1957,125,549-550$.

Merzenich, M. M., \& Harrington, T. The sense of flutter-vibration evoked by stimulation of the hairy skin of primates: Comparison of human sensory capacity with the responses of mechanoreceptive afferents innervating the hairy skin of monkeys. Experimental Brain Research, 1969, 9, 236-260.

Monjé, M. Ueber die Wirkung von Wechselströmen verschiedener Frequenz auf die Hautsensibilität. Zeitschrift für Physiologie, $1938,67,2-18$.

Mountcastle, V. B., Talbot, W. H., Sakata, H., \& Hyvärinen, J. Cortical neuronal mechanisms in flutter-vibration studied in unanesthetized monkeys. Neuronal periodicity and frequency discrimination. Journal of Neurophysiology, 1969, 32, $452-484$.

Piéron, H. La sensation. Paris: Presses Universitaires de France, 1967.

Piéron, H., \& Segal, J. Recherches sur la sensibilité tactile digitale par stimulation electrique du nerf cutané. Année Psychologique, 1938, 39, 89-135.

Rosner, B. S., \& Goff, W. R. Electrical response of the nervous system and subjective scales of intensity. In W. D. Neff (Ed.), Contributions to sensory physiology. Vol. 2. New York: Academic Press, 1967.

Scharf, B., \& Stevens, J. C. The form of the loudness function near threshold. Proceedings of Third International Congress on Acoustics. Vol. 1. Amsterdam: Elsevier, 1961.

Stevens, S. S., Carton, A. S., \& Shickman, G. M. A scale of apparent intensity of electric shock. Journal of Experimental Psychology, 1958, 56, 328-334.

Stoney, S. D., Jr., Thompson, W. D., \& Asanuma, H. Excitation of pyramidal tract cells by intracortical microstimulation: Effective extent of stimulating current. Journal of Neurophysiology, 1968, 31, 659-669.

Winkelmann, R. K. Similarities in cutaneous nerve end organs. In W. Montagna (Ed.), Advances in biology of skin. Vol. 1. Cutaneous innervation. Oxford: Pergamon Press, 1960.

(Received for publication December 11, 1972; revision received April 10,1973.) 